\title{
A new genus and new species of Baetidae (Ephemeroptera) from lakes and reservoirs in eastern North America
}

\author{
MATTHEW A. HILL ${ }^{1}$, JOHN PFEIFFER ${ }^{1} \&$ LUKE M. JACOBUS ${ }^{2,3}$ \\ ${ }^{\prime}$ EcoAnalysts, Inc., Moscow, Idaho, USA \\ ${ }^{2}$ Department of Biology, Indiana University, Bloomington, Indiana, USA \\ ${ }^{3}$ Corresponding Author.E-mail: lukemjacobus@alumni.purdue.edu
}

\begin{abstract}
Waynokiops dentatogriphus, new genus and new species (Ephemeroptera: Baetidae), is described from nymphs collected from seven lakes and reservoirs in the eastern United States of America, specifically from the states of Virginia, Kentucky, Ohio, Indiana and Arkansas (type locale), during sampling for the USEPA National Lakes Assessment. The lateral abdominal expansions and the dorsal abdominal armature of the new genus are unique among Cloeon complex genera. Abdominal tergal projections are unusual for a small minnow mayfly from lentic habitats.
\end{abstract}

Key words: Cloeon complex, identification, systematics, taxonomy, evolutionary novelty

\section{Introduction}

In 2007, the United States Environmental Protection Agency (USEPA) sampled over 1100 lakes in the continental United States of America as part of the National Lakes Assessment (NLA), a project to assess the overall status of the nation's lakes and evaluate the effects of selected stressors on lake condition. Field data collection for the project included selected chemical and physical parameters, and biological samples for later identification of phytoplankton, zooplankton, and benthic macroinvertebrates (USEPA, 2009). In 2008, EcoAnalysts, Inc. (Moscow, Idaho, USA) was awarded a contract for the taxonomic identification of a large portion of the biological samples collected for the NLA. During the processing of the benthic macroinvertebrate samples from this project, an unusual mayfly (Ephemeroptera) nymph that did not match any known taxonomic description was discovered from several sites in the eastern United States. The long antennae, the ventrally oriented dorsal lobe of the apex of the femur and the lateral ocelli being located posterior to the initial lateral branches of the epicranial suture all indicate placement in the family Baetidae (McCafferty, 1981; Wang \& McCafferty, 1996). In this paper, we name and describe this unusual small minnow mayfly.

\section{Material and methods}

Sampling for the NLA was conducted by crews contracted by EPA. Benthic macroinvertebrate sampling was done with a D-net. One meter sweeps were done at ten locations around the shoreline of each lake. Sampling was done in littoral areas and locations were evenly apportioned around the perimeter of the lake. The resulting material from the individual sweeps was composited into a single sample per water body and preserved in ethanol (USEPA, 2009). Each sample had a 500 count sub-sample randomly removed and identified. In those samples where the new mayfly was found, the remainder of the sample was searched for additional specimens. Subsequent sampling at the Tipton Lakes site conducted in the summer of 2009 failed to provide additional nymphs for rearing or molecular analysis. All specimens in our study were collected by 
EPA-NLA field crews. Material examined is deposited in the Illinois Natural History Survey, Champaign, Illinois, USA [INHS]; Purdue University Entomological Research Collection, West Lafayette, Indiana, USA [PERC] and the United States National Museum of Natural History, Smithsonian Institution, Washington, D.C., USA [USNM].

\section{Taxonomy}

\section{Waynokiops, new genus}

(Figs. 1-13)

Type species. Waynokiops dentatogriphus, new species.

Description. Nymph. Head: Frontal suture angle acute (Fig. 1). Mandibles with incisors cleft to base. Maxillary palp elongate and setose. Labial palp segment 3 with apicolateral corner produced. Thorax: Tarsal claw length subequal to length of respective tarus. Abdomen: Segments 1-7 expanded laterally; anterior terga with protrusions on posterior margins. Gills 1-7 bilamellate and somewhat rounded. Median filament with lateral setal fringes continuous throughout length. Cerci with medial setal fringe continuous throughout length.

Adults. Unknown.

Etymology. The new genus name refers to Lake Waynoka (U.S.A., Ohio, Brown County), one of the locales (but not the type locale) from which the species has been collected. The suffix "-iops" is from Greek, meaning small fish, a reference to the small minnow mayflies (family Baetidae).

\section{Waynokiops dentatogriphus, new species}

(Figs. 1-13)

Type material. HOLOTYPE: nymph (preserved in ethanol), ARKANSAS, Johnson County, Horsehead Lake, 26-VIII-2007 [USNM]. PARATYPES: five nymphs, same data as holotype [INHS].

Other material examined. U.S.A.: INDIANA, Bartholomew County: Tipton Lakes, 13-VIII-2007, one nymph [PERC]; Steuben County: Lake James, 24-VII-2007, one nymph [PERC]. OHIO, Brown County: Lake Waynoka, 2-VIII-2007, three nymphs [PERC, INHS]. VIRGINIA, Suffolk/Isle of Wight Counties: Burnt Mills Lake, 19-IX-2007, one nymph [USNM]. KENTUCKY, Christian County: Pennyrile Lake, 17VIII-2007, two nymphs [INHS].

Description. Nymph (preserved in ethanol). Body length of final instar: $4.5 \mathrm{~mm}$, excluding caudal filaments. Color: White with tiny, dark brown maculations scattered over dorsal surface.

Head (Fig. 1) narrow, hypognathous, coronal suture acute. Eyes protuberant, protruding beyond outline of head in anterior view (Fig.1). Antennae 2.5 times length of head. Pedicel and scape cylidrical, subequal in length. Labrum (Fig. 2) with shallow median excavation on distal edge. Mandibles (Figs. 3, 4) incisors cleft to base. Maxillae (Fig. 5) with palp narrow, attenuate and two-segmented. Lacinia stout, pointed, with comb of thick setae on distal half of medial edge below apical tooth. Apical tooth of lacinia 0.4 times length of lacinia. Labium (Fig. 6) with paraglossae slightly longer than glossae. Glossae convex laterally, medial margin straight in proximal half, concave distally, apex bluntly pointed. Paraglossae round at apex. Labial palp (Fig. 7) segment 1 rectangular, as long as segments 2 and 3 combined, and with peg-like setae on lateral surface. Segment two glabrous and 0.5 times length of segment 1 . Segment 3 distally explanate and truncate; lateral and distal margins densely setose; subequal in length to segment 2, with distal width 1.5 times proximal width; apicolateral corner with blunt, triangular tooth; tooth length subequal to width.

Pronotum (Figs. 8, 9) width 3.5 times length, with two pairs of low mounds, one pair sublaterad of midline and one pair near lateral margins. Mesonotum (Figs. 8, 9) roughly sculptured, with median, longitudinal ridge slightly projected in lateral aspect. Hind wingpads absent. Legs (Fig. 10) with femur 5 times longer than wide; 
femur with ventral row of short, lanceolate setae and with sparse distribution of fine setae dorsally. Patellotibial region of mesothoracic leg as in Figure 13. Tibia and tarsus subequal in length and width, each bearing ventral row of pectinate, lanceolate setae, and with sparse distribution of dorsal fine setae. Tarsal claw slightly curved, subequal in length to tarsus, with two rows of tiny denticles (Fig. 11) restricted to proximal 0.25 length.
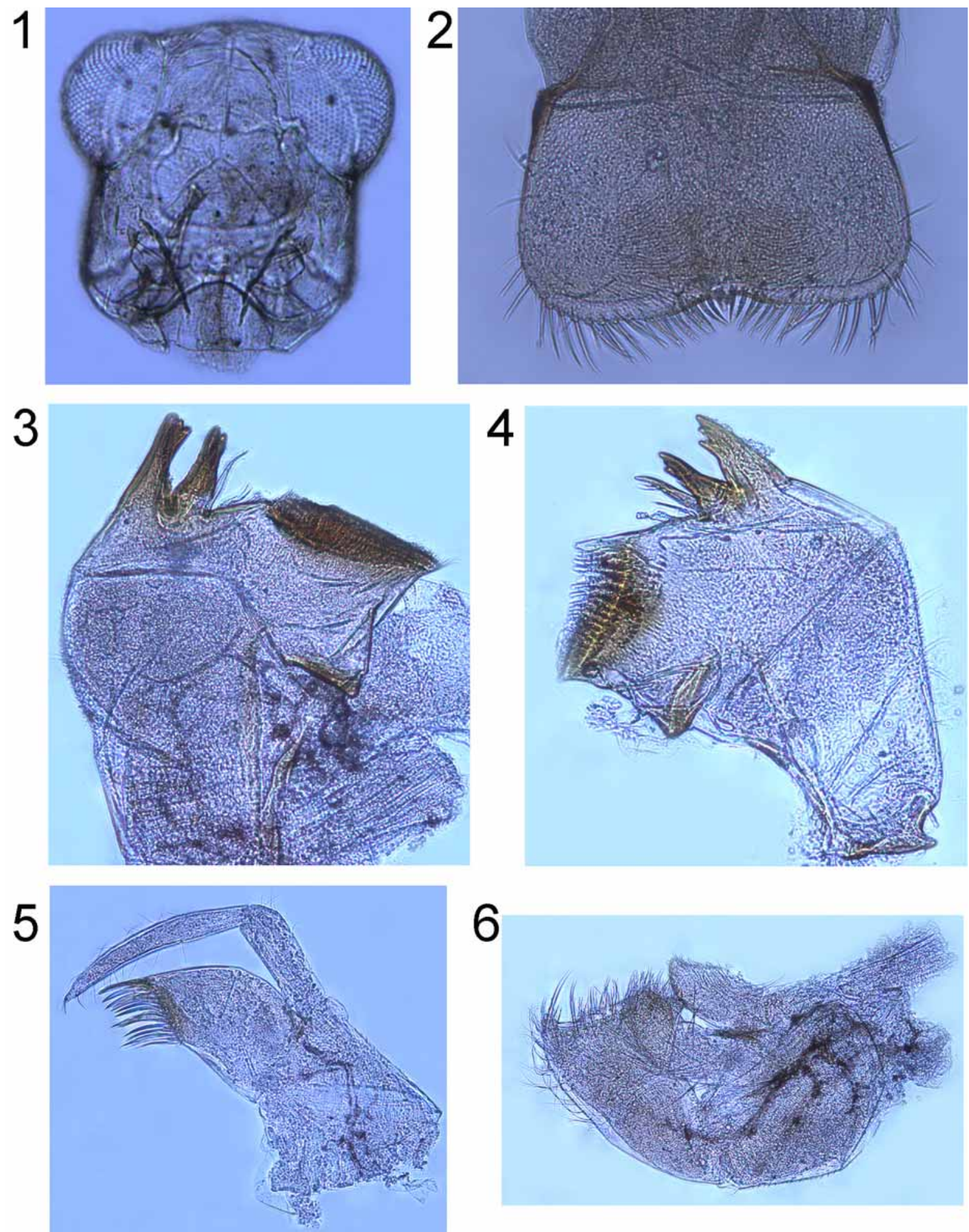

FIGURES 1-6. Waynokiops dentatogriphus, new genus, new species. 1. Head, anterior view, cleared and with mouthparts removed. 2. Labrum. 3. Right (planate) mandible. 4. Left (angulate) mandible. 5. Maxilla. 6. Labium. 

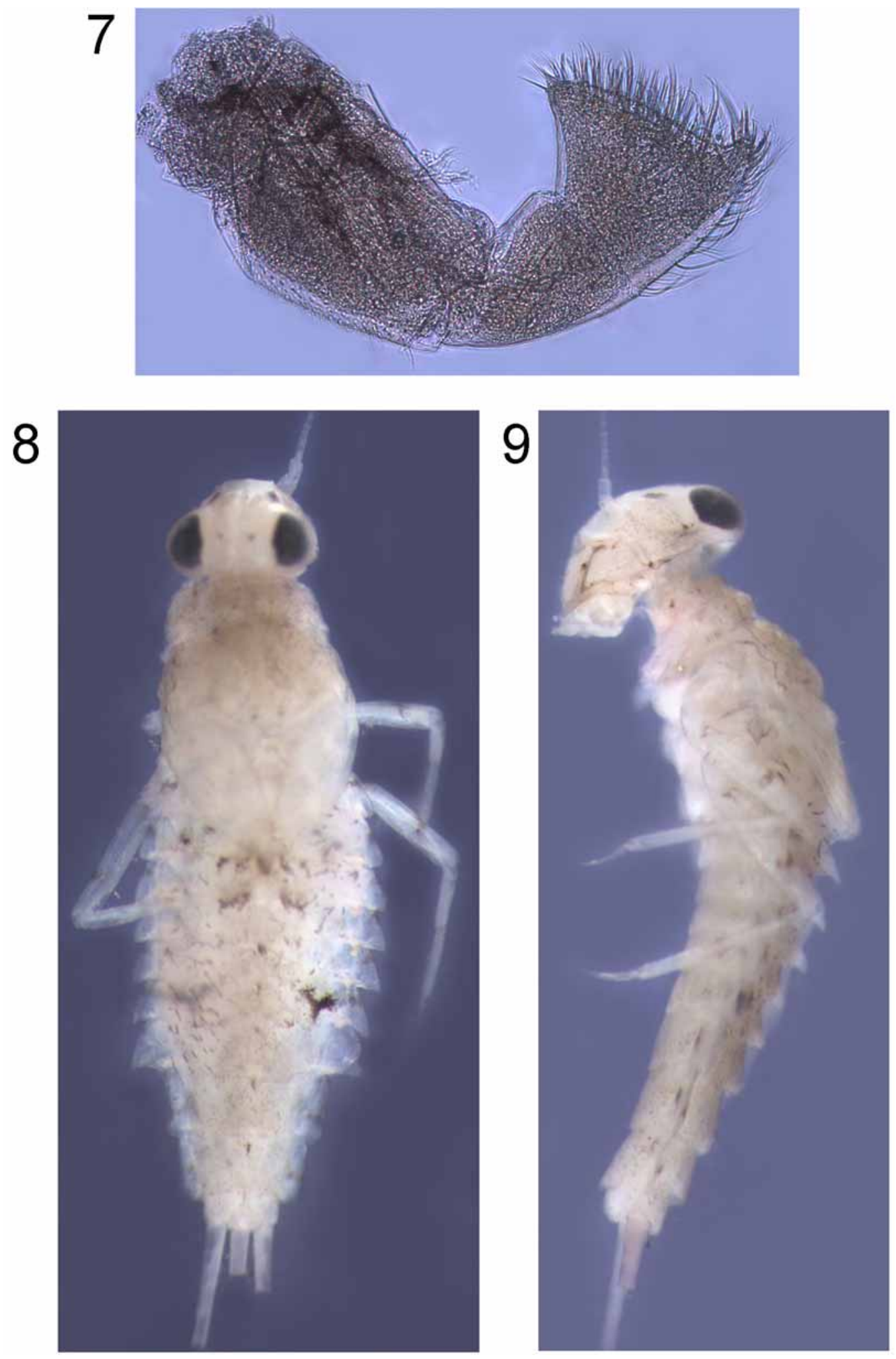

FIGURES 7-9. Waynokiops dentatogriphus, new genus, new species. 7. Labial palp. 8. Dorsal view, whole. 9. Lateral view, whole.

Abdomen dorsoventrally compressed. Segments 1-9 each with dark, transverse band on lateral margins (most apparent on later instars). Triangular, acute, posteriorly-directed lateral expansions present on segments 1-7 and parallel-sided lateral flanges present on segments 8-9 (Fig. 8). Lateral processes on segment 7 with stout spinules on posterior margins. Lateral expansions of segments 8 and 9 with stout spinules on posterior 

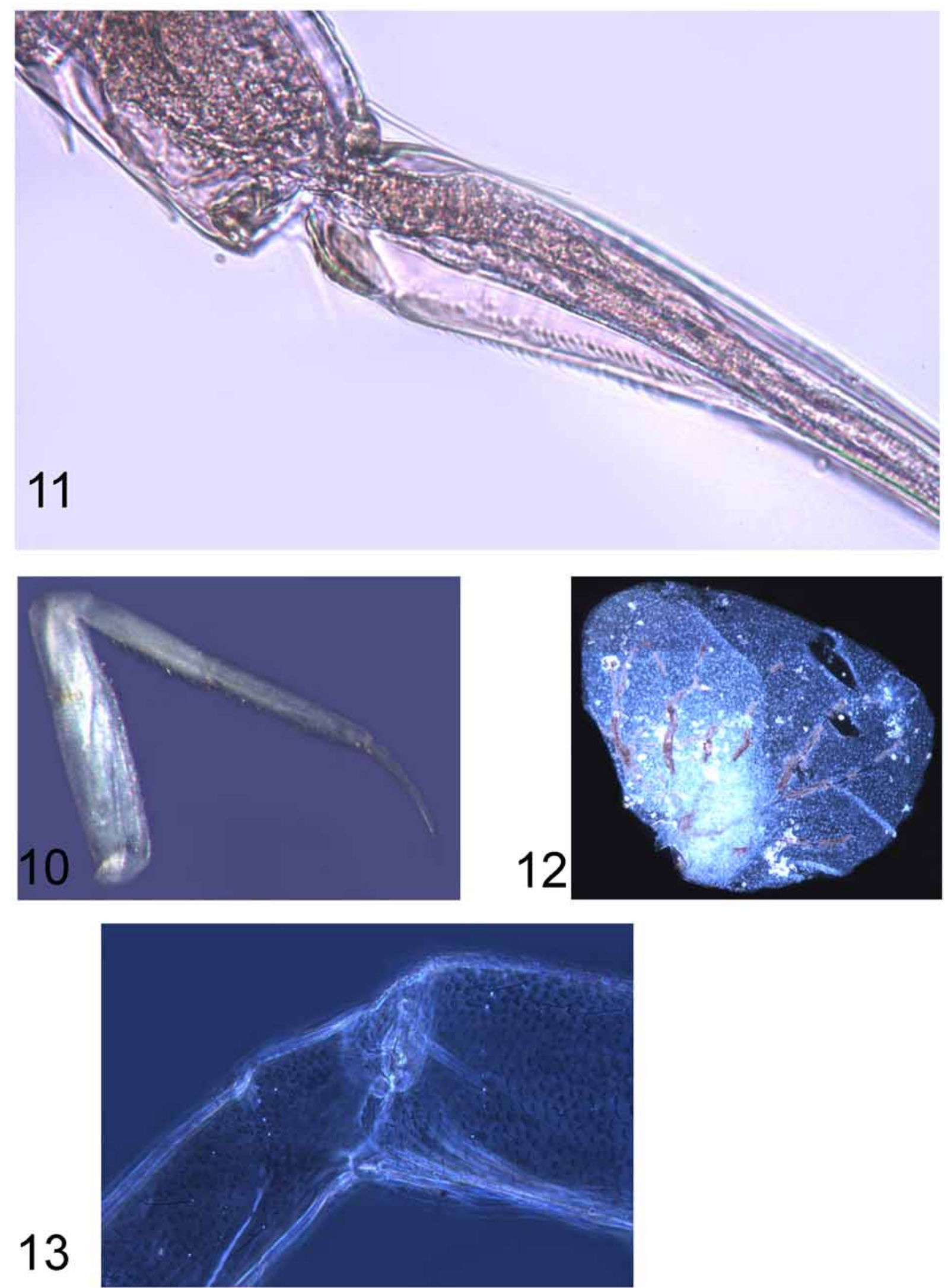

FIGURES 10-13. Waynokiops dentatogriphus, new genus, new species. 10. Mesothoracic leg. 11. Tarsal claw; note double row of denticles restricted to proximal quarter of claw. 12. Gill VI. 13. Mesothoracic leg, patellotibial region. 
half of lateral margins and on free posterior margins. Such stout spinules sometimes present on more anterior segments. Single, median, erect, posteriorly hooked spines present on terga $1-6$, decreasing in relative development posteriorly (Fig. 9). Broad, bilamellate gills (Fig. 12) present on abdominal segments 1-7. Dorsal lamella of gills round, approximately half size of lower lamella. Lower lamella triangular, with broken, branched venation. Cerci and median filament (Fig. 8) pale with numerous, narrow faint darker bands. Median filament with lateral setal fringes continuous throughout length. Cerci with medial setal fringe continuous throughout length. Caudal filaments subequal in length to each other, and to length of abdomen.

Adult. Unknown.

Etymology. The specific epithet is a combination of the Latin word dentatus, meaning toothed, and griphus, meaning riddle. This name is a reference to the prominent median protuberances on the abdominal terga, and to the puzzling morphology and phylogenetic position of the species. The gender is masculine.

Morphological variability. The stout spinules of the lateral and sometimes posterior margins of abdominal terga vary in the size and number per segment. The spinules are smaller and fewer in number on more anterior segments. One specimen (U.S.A., Indiana, Bartholomew County) has such spinules present as far anteriorly as segment two; however, most specimens do not have them appear this far anteriorly. The spinules usually begin to appear around segment 6 . Later instars have larger and more numerous spinules. Likewise, the single, median, erect, posteriorly hooked spines present on the abdominal terga vary in their relative development.

Diagnosis. The monotypic new genus is distinguishable from all other Baetidae by having the following combination of characters: somewhat truncate and expanded labial palp segment 3 (Fig. 7), variously developed lateral spinules on the abdomen (Gillies, 1990: Figs. 2, 3), laterally expanded abdominal segments (Fig. 8) and medial armature on the abdominal terga (Fig. 9).

We modify a recent and widely-used key to genera of North American mayfly nymphs (Waltz \& Burian, 2008) to accommodate Waynokiops, new genus, as follows, because an impasse is reached at couplet 24.

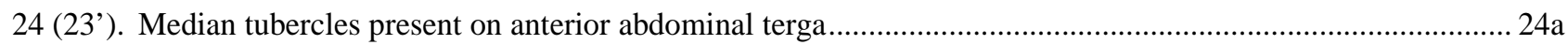

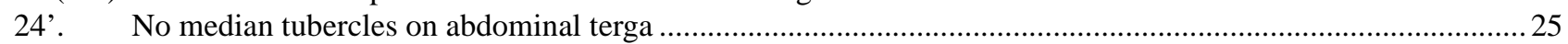

24a. Abdominal gills (or gill sockets) present on segments 1-5 only; gills extend ventrally from the pleura; Southwest, Texas, Utah .......................................................................................... Baetodes Needham \& Murphy

24a'. Abdominal gills (or gill sockets) present on segments 1-7; gills held dorsally; Central and East ...

Waynokiops, new genus

Discussion. The new genus is part of the Cloeon Leach complex of genera. This possibly monophyletic group (reviewed in parts by Kluge \& Novikova, 1992; Monaghan et al., 2005; Gattolliat et al., 2008; Ogden et al., 2009: Figs. 3, 6) is defined here to include those Baetidae that have nymphs with the following synapomorphies (Kluge and Novikova, 1992): an at least somewhat truncate and expanded labial palp segment 3 (similar to Figure 7) and variously developed lateral spinules on the abdomen (Gillies, 1990: Figs. $2,3)$. These spinules sometimes are minute and restricted to only one or two segments. Caudal filaments with dark rings on about every fourth segment may be another synapomorphy of the Cloeon complex genus groups, but our few nymphs with intact caudal filaments were faded, and we could not evaluate the character with confidence. Worldwide, the Cloeon complex includes Waynokiops, new genus, Cloeon Leach, Centroptilum Eaton [=Neocloeon Traver], Similicloeon Kluge \& Novikova, Intercloeon Kluge \& Novikova, Pseudocentroptilum Bogoescu, Procloeon Bengtsson, Pseudocentroptiloides Jacob [=Psammonella Glazaczow] and Securiops Jacobus, McCafferty \& Gattolliat. In North America, species of the Cloeon complex are classified into the genera Cloeon, Centroptilum, Procloeon, Pseudocentroptiloides and now, Waynokiops, new genus. Globally, the rank and application of these names varies among current Ephemeroptera specialists.

Our new genus has characteristics that Kluge \& Novikova (1992) considered separately apomorphic for the genus groups Cloeon and Centroptilum, namely the expanded gills, mandibles with incisors cleft to bases and shapes of labial palps. Thus, we advocate critical evaluation of these characters with regards to their use and interpretation in phylogenetic inference. We also call attention to the apical projection on labial palp 
segment 3 and its similarity to a potentially a homologous structure in Securiops (Jacobus et al., 2006: Figs. 6, 14). Notably, Securiops also has mandibles with deeply cleft mandibular incisors (Jacobus et al., 2006: Figs. $8-11)$.

Our new genus demonstrates autapomorphies, including the expanded abdominal segments $1-7$ and the dorsal abdominal armature. Dorsal abdominal armature on a baetid nymph from lentic habitats is of particular interest, because thusfar, such armature has been found only within genera whose nymphs are associated with lotic habitats. These genera include Acentrella Bengtsson, Acanthiops Waltz \& McCafferty, Afrobaetodes Demoulin, Baetiella Ueno, Baetodes Needham \& Murphy, Cheleocloeon Wuillot \& Gillies, Dicentroptilum Wuillot \& Gillies, Echinobaetis Mol, Gratia Thomas, Jubabaetis Muller-Liebenau, Papuanatula Lugo-Ortiz \& McCafferty, Tanzaniops McCafferty \& Barber-James and Thraulobaetodes Elouard and Hideux (Thomas, 1992; Waltz \& McCafferty, 1987; Wuillot \& Gllies, 1993; Boonsoong et al., 2002; McCafferty, 2003; McCafferty \& Barber-James, 2005; Jacobus \& McCafferty, 2006).

\section{Acknowledgments}

We thank J.-L. Gattolliat (Musee de Zoologie, Lausanne, Switzerland), G. Lester (EcoAnalysts, Moscow, Idaho, USA), W. P. McCafferty, A. V. Provonsha (Purdue University, West Lafayette, Indiana, USA) and J. Webb (LaTrobe University, Wodonga, Victoria, Australia) for valuable discussion. Two anonymous reviewers provided valuable criticism for improvement after the manuscript was submitted for consideration for publication. Ellen Tarquinio (USEPA) granted permission to publish these data from the National Lakes Survey. William W. Jones (Indiana University, Bloomington, Indiana, USA) discussed sampling protocols and provided logistic assistance. The Tipton Lakes Community Association (Columbus, Indiana, USA) granted permission for fieldwork at the Bartholomew County, Indiana, location. Barbara L. Hass (Indiana UniversityPurdue University at Columbus, Indiana, USA), Alayna A. Jacobus (Nashville, Indiana, USA) and Thomas Parr (Indiana University, Bloomington, Indiana, USA) provided assistance during 2009 sampling.

\section{References}

Boonsoong, B., Thomas, A. \& Sangpradub, N. (2002) Gratia narumonae n. sp., a new mayfly from Thailand (Ephemeroptera, Baetidae). Ephemera, 4, 1-9.

Gattolliat, J.-L., Monaghan, M.T., Sartori, M., Elouard, J.-M., Barber-James, H., Derleth, P., Glaizot, O., de Moor, F. \& Vogler, A.P. (2008) A Molecular analysis of the Afrotropical Baetidae. In: Hauer, F.R., Stanford, J.A., \& Newell, R.L. (Eds.), International Advances in the Ecology, Zoogeography and Systematics of Mayflies and Stoneflies. University of California Publications in Entomology, vol. 128, pp. 219-232.

Gillies, M.T. (1990) A revision of the African species of Centroptilum Eaton (Baetidae, Ephemeroptera). Aquatic Insects, $12,97-128$.

Jacobus, L.M. \& McCafferty, W.P. (2006) A new species of Acentrella Bengtsson (Ephemeroptera: Baetidae) from Great Smoky Mountains National Park, USA. Aquatic Insects, 28, 101-111.

Jacobus, L.M., McCafferty, W.P. \& Gattolliat, J.-L. (2006) Taxonomy of Afrotropical Securiops, new genus, and Cloeodes Traver (Ephemeroptera). African Entomology, 14, 129-140.

Kluge, N. \& Novikova, E.A. (1992) Revision of Palearctic genera and subgenera of mayflies in the subfamily Cloeoninae (Ephemeroptera, Baetidae) with descriptions of new species from the USSR. Entomologicheskoye Obozreniye, 71, 60-83.

McCafferty, W.P. (1981) Distinguishing larvae of North American Baetidae from Siphlonuridae (Ephemeroptera). Entomological News, 92, 138-140.

McCafferty, W.P. (2003) Gose's African Ephemeroptera (Baetidae, Heptageniidae). Entomological News, 113, $294-302$.

McCafferty, W.P., \& Barber-James, H.M. (2005) Tanzaniops, replacement name for certain African Baetidae (Ephmeroptera). Proceedings of the Entomological Society of Washington, 107, 238.

Monaghan, M.T., Gattolliat, J.-L., Sartori, M., Elouard, J.-M., James, H., Derleth, P., Glaizot, O., de Moor, P.F., \& Vogler, A.P. (2005) Trans-oceanic and endemic origins of the small minnow mayflies (Ephemeroptera, Baetidae) of Madagascar. Proceedings of the Royal Society, B, 272, 1829-1836.

Ogden, T.H., Gattolliat, J.L., Sartori, M., Staniczek, A.H., Soldán, T. \& Whiting, M.F. (2009) Towards a new paradigm in 
mayfly phylogeny (Ephemeroptera): Combined analysis of morphological and molecular data. Systematic Entomology, 34, 616-634.

Thomas, A. (1992) Gratia sororculaenadinae n. gen., n. sp., Éphéméroptère nouveau de Thaïlande (Ephemeroptera, Baetidae). Bulletin de la Société d'Histoire Naturelle de Toulouse, 128, 47-51.

United States Environmental Protection Agency (USEPA). (2009) National Lakes Assessment: A Collaborative Survey of the Nation's Lakes. EPA 841-R-09-001. USEPA, Office of Water and Office of Research \& Development, Washington, D.C.

Waltz, R.D. \& Burian, S.K. (2008) Chapter 11, Ephemeroptera. In: Merritt, R.W., Cummins, K.W. \& Berg, M.B. (Eds.). An Introduction to the Aquatic Insects of North America, Fouth Edition. Kendall/Hunt, Dubuque, Iowa, pp. 181236.

Waltz, R.D. \& McCafferty. W.P. (1987) Systematics of Pseudocloeon, Acentrella, Baetiella, and Liebebiella, new genus (Ephemeroptera: Baetidae). Journal of the New York Entomological Society, 95, 553-568.

Wang, T.Q. \& McCafferty, W.P. (1996) New diagnostic characters for the mayfly family Baetidae (Ephemeroptera). Entomological News, 107, 207-212.

Wuillot, J. \& Gillies, M.T. (1993) Cheleocloeon, a new genus of Baetidae (Ephemeroptera) from West Africa. Revue d'Hydrobiologie Tropicale, 26, 213-217. 